\title{
The Rise of Smart Factories in the Fourth Industrial Revolution and Its Impacts on the Textile Industry
}

\author{
Ömer Faruk Görçün
}

\begin{abstract}
Globalization is a process that has continuity, even though interrupted sometimes. Globalization has no loyalty to anything and this is its most prominent feature of globalization. It tries to create new paradigms according to new conditions of ages. Globalization can easily adapt to new situations. The fourth industrial revolution will begin in a very short time and will lead to a change in industrial, social and economic lives of people. This may create new industrial relations between capital and labour. The most important components of the fourth industrial revolution are smart factories, e-production applications and interaction between smart systems for excellent production processes. This research focuses on e-applications in the production process of textile industries from orders to delivering of goods.
\end{abstract}

Index Terms-Fourth industrial revolution, textile industries, e-applications, internet of things (IoT).

\section{INTRODUCTION}

Advancements in the fields of technology have led to the improvement of industries in terms of industrial productivity and efficiency since the dawn of the industrial revolution. The steam engine used in factories had reduced the need for the human force and have taken its place. The first industrial revolution occurred by the end of the 18th century with the mechanization of the manufacturing processes [1]. In the following years, industries gained the capability for mass production with the use of electricity. After 1980, industries became rapidly automated. The most important changes in the industries have been observed since the IT revolution which began at the end of 1990 .

In this period, industries have become more technological. Also, advanced technological elements have provided opportunities to respond to customer's demands. The most important indicators of this period may be defined as e-commerce, IT, mobile communication and, advanced internet infrastructure.

Humanity is on the eve of a new age. In the era we live, the supply, production and consumption processes are rapidly changing. Nowadays, we are about to experience another transition which may lead to great changes in all aspects of our lives. Not only can it cause transformation in industrial activities but also may lead to change in the fields such as commerce, logistics and consumption. In fact, these changes are a result of the new role played by customers in the value chains. Today, the consumption function has become more important compared to the production. The dominant role of

Manuscript received November 25, 2016; revised April 7, 2017.

Omer F. Görçün is with the Kadir Has University, Faculty of Applied Science, CO 34083 Turkey (e-mail: omer.gorcun@ khas.edu.tr). consumers may continue to be decisive for value chains in the future. Now, all the supply chain operations and industrial activities are conducted according to customer satisfactions and expectations. Markets are facing an increasing need for individualized products [2]. Customers do not want to buy standard products and demand more personalized and customized products and services. In parallel, industrial processes and supply chain operations have to be re-designed according to these new paradigms.

In order to achieve the speed and flexibility required by competition, technology has become one of the most important components of the industry in this period. Today, the convergence of the physical and virtual world is possible as a result of technological improvements. On the other hand, all physical objects are becoming digital. The evolution towards Industry 4.0 is mainly based on digital technologies. Basic ideas and concepts of Industry 4.0 will be presented, including aspects like horizontal integration through value networks, end-to-end digital integration of engineering across the entire value chain and vertical integration and networked manufacturing systems.

This new period called industry 4.0 has removed all paradigms of the previous period and created new paradigms related to production and consumption. Prior to the smart manufacturing of Industry 4.0, numerous other advanced manufacturing schemes have already been proposed for overcoming the drawbacks of the traditional production lines, for example, the flexible manufacturing and the agile manufacturing [3]. Industry 4.0 or the fourth industrial revolution has emerged as a result of technological improvements. It is a complicated term embracing the cyber physical systems, the internet of things, smart factories, and Big Data. Fourth industrial revolution is trying to perfect all the processes, such as supply, production, consumption, and logistics. The best way to achieve this end is to increase the technological level of factories. In this way, decreasing the human factor which causes various errors is possible.

Textile and clothing industry has faced the problems of using intense human power, and the lack of technology. As a result of these, the level of productivity and efficiency of these industries is insufficient. Since textile industries do not have flexible operational structure, they cannot balance their flows and therefore they are not strong enough before high competitive pressure. At the same time, we are facing new challenges: our products need to be more individualized and offered in more variations, they must be adjusted to market requirements in shorter time, the product life cycles are shorter than ever before and the global competition ever stronger [4]. On the other hand, they show a high dependence on the labour force. Therefore, human errors are concentrated 
in supply, production and logistics processes. In addition to that, the varying level of customer expectations and demands is extremely high. Nobody wants to buy clothing products purchased by another customer. Therefore, industries have to make special product designs and should manufacture personalized products.

Industry 4.0 may help to textile and clothing industries to solve these problems. With the redesign of the industrial processes according to industry 4.0 and technological advances, all the processes related to production and logistics may become more flexible, rapid and agile in textile value chains. Textile and clothing industries may obtain significant flexibility and can give quick and effective responses to the customer's needs as a result of the transformation of their production and logistics processes. Transformation of textile industries depends on the use of high technology in production and logistics processes within the framework of technological advancements emerging as a result of Industry 4.0. Therefore, textile value chain should be re-designed and re-structured according to the new requirements and paradigms of this industrial revolution.

The fourth industrial revolution has several components such as internet of things IoT, big data, cyber-physical systems, smart factories and robotics. If textile and clothing industries can keep pace with these technological improvements, they may obtain various strategic advantages.

\section{INDUSTRY 4.0}

The fourth industrial revolution is an important milestone in the human history. It causes changes in almost all aspects of our lives and will continue to play its role in the future. Until now, it has led to changes in industrial processes, in structural features of value chains and logistics operations. Industry 4.0 can be defined as the integration of high technological systems such as communication, computers, the internet, identification and cyber-physical systems. Integrated high technological systems may lead to more effective production processes and logistics operations. All the processes of the supply chain may be harmonized with the use of high-technology.

Industrial activities focus on customer expectations and preferences in the process of the fourth industrial revolution. Industries can respond more effectively to customer's demands and needs by monitoring the changes in the markets and demands. The main philosophy of industry 4.0 is the creation of perfect and autonomous production processes integrated with high technological elements. Secondly, one of the most important elements of the industry 4.0 is digitalization. All objects related to the physical world can be transferred to the virtualized world. As a result of this, all industrial processes including product design can be complete with the use of information-processing systems. The main aim of the fourth industrial revolution is to configure the autonomous and intelligent production systems thanks to smart factories. According to approaches of the industry 4.0, customer behaviour may shape the supply chains operations. If a customer takes a product from the shelf, sensors and identification systems can detect this situation and can transfer it to information systems as data. Immediately after, this data can be used for production and other logistics activities.

This data may be a factor to start or stop industrial operations such as production and logistics in an autonomous way. All obtained data related to customer preferences can be defined as a command system. Depending on this command system, all machines can automatically start working and when the process is finished, machines can stop automatically. As well as digitalization, integration between virtual and physical worlds are expected to play a key role in the next industrial revolution. This integration can only be possible with the internet of things.

\section{INTERNET OF THINGS (IOT)}

All industries are trying to use advanced technology to improve their industrial operations and find the best way to provide the integration between technological elements and their production processes. In our age, industries have focused on these technological improvements and they are trying to increase the investment on technological instruments related to industry 4.0. Internet of things IoT is one of the most important elements for value chain as well as for industries.

Internet of things can be defined as communication among devices, machines, and equipment with their virtual personalities and capabilities obtained as a result of technological advances. These physical systems have become smart and can automatically conduct some industrial operations as a result of these connections. To start or stop industrial and logistics operations may be possible by the connection between these devices and machines without human force or decision-making process. Internet of things is a process that starts with the emergence of various defined conditions or movements. All data related to movement and situations are detected by sensors and are automatically sent to the system for data processing. Previously, all conditions have been described in the system numerically by operators. For example, when you buy a bottle of milk from a shelf of the supermarket, sensor scans the smart tag and they detect this movement. Simultaneously, this data related to your purchase is sent to the machines of the manufacturer as a command that marks the start of the manufacturing process. Each machine sends the command to the next machine by internet of things saying: This operation conducted by me must be completed, start immediately. I'm sending you the unfinished product.

Thanks to IoT physical objects are seamlessly integrated into the information network where they can become active participants in business processes [5]. Finally, internet of things can provide opportunities of integration between all operational processes such as production and consumption in the value chains. More importantly, industries can be informed about their customer's expectations and demands. Obtaining real-time information about customer's demands and expectations is easy as a result of the effective use of this technology. Real-time information related to changes occurring in markets can increase awareness of the industries. They can give an accurate and effective response to these 
changes. Industries can take the right position when faced with this kind of threats as a result of uncertainty in the markets.

\section{CYBER-PHYSICAL SYSTEMS}

Cyber-physical system (CPS) is a rapidly growing interdisciplinary area combining major aspects of control, systems, electronics and computer science [6]. Cyber Physical Systems (CPS) are automated systems that enable the connection of the operations of the physical reality with computing and communication infrastructures [7]. Cyber physical systems can also be defined as a technological system. It can give an opportunity for monitoring, and controlling all processes of the value chain simultaneously. This system can also be used for computation, optimization, and communication. With the use of these systems, all operations occurring in value chains can be optimized. These systems may lead to integration between physical industrial elements such as machines and cyber technologies. The integration of physical machines and cyber technologies can be possible with these cyber-physical systems. In this way, machines used in production processes can become more intelligent as well as factories and they can be defined as the smart system and the smart factories. Unlike traditional embedded systems designed as stand-alone devices, the focus in CPS is on networking several devices [8].

\section{SMART FACTORIES}

When advanced technologies such as big data, intelligent robots, and virtual personal assistants were taken into consideration, all industrial structures were transformed into smart factories, and all physical production systems gained more intelligent characteristics. With the integration between the physical and the virtual world, industrial processes, machines used in the manufacturing processes and factories have become more intelligent. Nowadays, all industrial processes have become more automatic. High-technologies have led to the creation of new production systems which have the most autonomous characteristic. Today, the most important principal of smart factories is coordination and interaction between all operations realized from the supplier to the customer. The basis of the smart factories is the cyber physical systems. In other words, cyber-physical systems can be defined as the heart of the smart factories. These systems can solve highly complex problems related with supply chain operations and production. Physical industrial conditions can be modelled in the virtual environment thanks to digitalization. Before the physical production, all production processes can be created in the virtual world. In this way, the positive and negative situations which may occur in the physical production process can be detected. Finally, determining the measures according to potential risks and problems may be possible. In addition to that, all factors as machines, human force, equipment and industrial processes can be optimized in this way, idle capacity would not be possible in manufacturing activities. As a result, efficiency and productivity can be achieved at the highest level in all industrial processes.

New production processes should be re-designed in the framework of the more intelligent manufacturing systems. Therefore, real-time information is the most important necessity for smart factories. In accordance with this, industries are trying to create a new information flow system. Real-time information should be collected with identification systems and sensors, and must be processed simultaneously. In addition to that, digital characteristics can be embedded in physical products. In this way, real-time information can be collected from products directly. Additionally, by creating a digital identity, a product in the process of manufacturing can carry its digital memory throughout its life cycle and can communicate with its environment. Collecting and processing of real-time information may be possible and information flow system may become lean and more functional in this way.

Smart factories will lead to changes in manufacturing and logistics processes. Initially, creating a perfectly functioning material flow systems is possible. Secondly, all processes between supplier and customer may be re-organized in terms of productivity. In addition to that, smart factories will offer an improved working environment in terms of safety. Manufacturing systems can become smart depending on the technologic advancements. Intelligent machines that can take optimal decisions automatically are the key elements of the smart factory. And also, some key technological advancements such as robotics technologies, automation systems, identification systems and communication systems which provide interaction between machines and humans can provide an opportunity to create a more intelligent production system. Automation, robotics systems and autonomous behaviour of machines are the most important elements of the smart production systems.

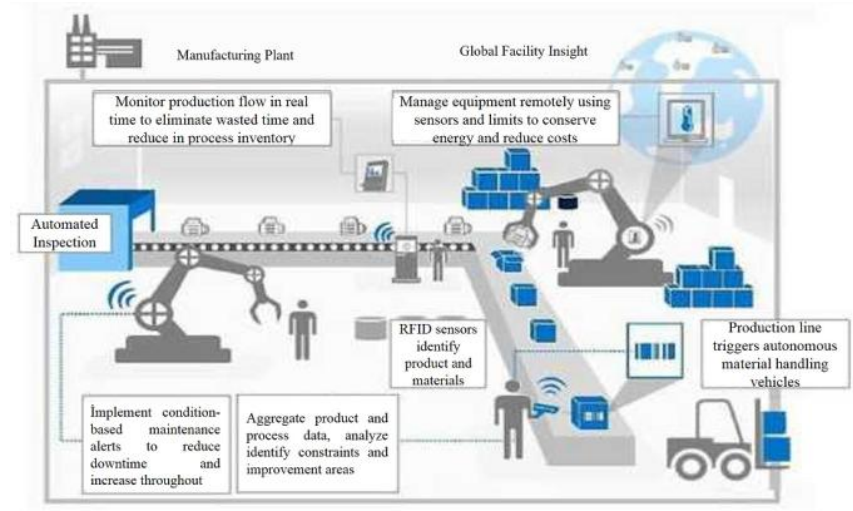

Fig. 1. Smart Factory and operations, Source: Microsoft IoT in manufacturing infographic, 2015.

Robots lack intelligent characteristics although they have been utilized in production systems for a long time. In the past, robots were not autonomous and did not have a function without an operator. They were only used as a mere mechanics' production system. Reducing the use of manpower in production processes have become possible with the use of robots. In the past, expectations regarding robots were extremely limited. However, robots used in the past cannot be compared with today's high-tech robots. Today's robots have highly sophisticated and complex 
functions.

The current robotics systems can solve very complex problems and can take optimal decisions automatically. Today's high-tech robotic systems will adapt to value chains. More importantly, the interaction between robots and machines including devices will be possible. On the other hand, robots can be able to communicate with materials such as raw-material, semi-product or products. In addition to that, they can lead to the redesign of logistics processes. In the future, all operations carried out in the value chain will become a trigger for each other and automatically be carried out without human intervention. All industrial activities and supply operations, as well as logistics operations, may be carried out by autonomous systems and robotics. These systems can collect perfectly accurate information relating to customer demands and expectations from different sources. This information can be converted to data used in the manufacturing process after its analysis by the systems. Robotics systems can send command to other machines and robots in relation to their functions. As a result of this, the whole supply, production and consumption processes can be completely integrated and become more systematic. Consequently, all machines and equipment utilized in logistics and production operations can be used at full employment.

Another important development in the field of technology can be seen in the communication systems related to smart factories. In the past, communication among humans or between human and machines were possible. However, communication would be unthinkable without humans. As a result of this, human factor may cause disruptions in communication and lead to various problems related with human failures. Today's technological advances can give an opportunity to solve these problems through seamless communication. Communication and interaction among machines have become possible as a result of technological advances. It can be defined as machine to machine (M2M).

Technological advancements, especially mobile devices, have solved some of the central technological limitation problems in recent years [9]. Thanks to communication among machines, conventional factories began to transform into intelligent factories and they have become smart factories. This communication system includes devices providing real-time information related to markets and customers. One of the main functions of devices is to collect this information. Also, transferring the information to the data processing system is another function of devices. Communication among machines is rapidly developing with the development of the internet technology. Increases in data transfer rate can lead to the further development of these systems. This communication system is one of the most important parts of the industrial internet concept and is also known as the internet of things.

One of the most important components of the M2M communication system is their identification system. There are various functions of identification systems. Collecting and transferring information relating to market or customer conditions is the important function of the identification systems. This system is known as radio-frequency identification (RFID). This identification system has some components such as RFID tags, readers and antenna. Radio Frequency Identification system can be used for the monitoring and identification of almost all objects. At the same time, it is a remote sensing system and can realize its functions without touching objects. When a material in which a microchip is embedded comes within the range of the machine, it can send a signal to the machine. Actually, these signals are data sent by RFID tags. Machines can detect these signals and they can perform their functions in accordance with these signals. The communication is possible between all machines and materials and it can be provided by the wireless internet.

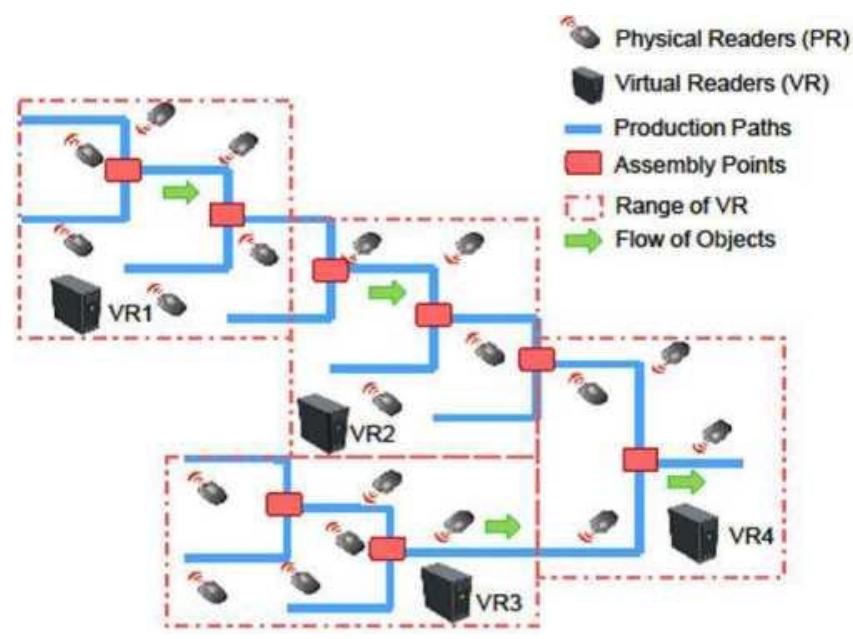

Fig. 2. Factory deployment of RFID based real-time production tracking framework, [10].

RFID technology has been used in production process to carry out the more organized and systematic material flows in the last decades. This system may provide an opportunity to create a perfect manufacturing system. Microchips which are embedded in products send the signal to machines. To start or stop the operation of the machine may be possible with data sent by RFID tags.

\section{THE FOURTH INDUSTRIAL REVOLUTION AND THE TEXTILE AND CLOTHING INDUSTRY}

Due to the intensive use of labor and the rising total costs, competitive capacity of world's manufacturing industry weakens. On the other hand, total adding added value which created in the value chains may be reduced as a result of increased costs. Industry 4.0 focuses on manufacturing activities related to the automotive industry. Actually, the need for new production techniques and approaches is much more in textile industry. Industry 4.0 will have a direct effect on producers and their labor force as well as on companies supplying manufacturing systems [11]. Observed increases in the level of labor use may cause increase in total costs. Also, more errors in manufacturing process may occur because of intensive labor use. More importantly, the new dominant role of customers has been affecting the manufacturing processes of the textile industry. Standard products are not preferred by today's customers. Usually, they demand personalized and customized products. In the near future, all textile industries will have to keep pace with these demands. Consequently, changes in manufacturing processes will be inevitable in the 
textile industry. In the near future, key technologies related to smart factories such as automation, machine to machine communication systems, and robotics technology will be essential for the improvement of the textile value chains as well as textile manufacturing systems.

With the use of advanced technology many independent manufacturing processes and logistics operations will have completely integrated with each other when factories become smarter. Firstly, RFID tags should be embedded to products or packing of the products. For this, various elements as containers, bobbins, and clothes hangers may be used. RFID tags embedded in products may store a lot of information related to products, manufacturing process, and logistics operations. This information can be collected by sensors placed on the machine or anywhere after reading. When the RFID tags embedded in materials are read by the sensor, it sends this information to machines as a command. In this way, machines can fulfil the functions expected from them automatically.

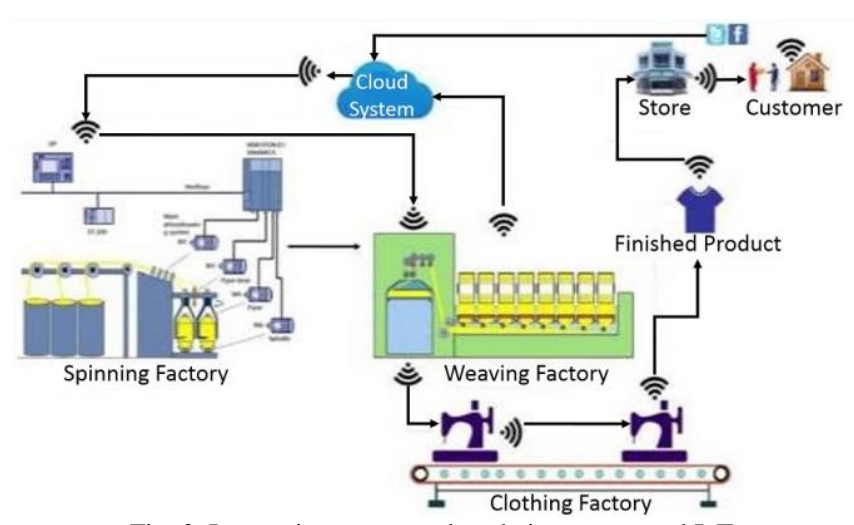

Fig. 3. Integration among value chain process and IoT.

Technologic applications are not only used in manufacturing activities but also may they help to create the optimal material flow system from the supplier to the consumer. Hence, their scope is much wider. When the last operation related to manufacturing activities is finished, sensors may send this information to conveyors as a command for the products to be carried to the shipping point. After the product comes to this point, it is scanned by another sensor. Real-time information related to shipment is sent to the transportation unit such as trucks, ships, rail wagons or cargo planes. In this way, the preparation process relating the physical transportation operation can be complete before the final product output operations. Manufacturing and logistics operations in the value chain could be self-optimized. More importantly, self-configuration of these processes in accordance with variable conditions is possible thanks to these technological systems. As a result, companies can respond to customer demands more easily and flexibly.

In line with this, smart factories can reduce the energy consumption in the manufacturing process. This can be possible in two ways. In the past, machines continuously worked until the end of overtime. Since machines unceasingly worked even if there was no production activity energy consumption was very high in the past. Therefore, energy consumption costs have become intolerable in textile and clothing industries. Thanks to today's production systems based on advanced technology, machines can automatically start to work when there is a production activity and when it is finished they can have switched to the standby mode automatically.

Usually, standby time of machines may be longer than the working time in many industries such as the textile and clothing industries. As a result of this, energy costs and energy consumption may greatly be reduced in the textile manufacturing industries. When the human force is intensively used in manufacturing processes, humans can perform the activities relating to production only in the perfectly lit workplace. They cannot work in dark environment. Whereas, machines can fulfil their functions without the need to light. Lighting of the workplace is not necessary for the smart factory. In this way, energy needs of the textile industry may be reduced.

Smart textile factories can allow the optimal use of available sources to meet customer's requirements. Today's customer's demands and expectations are extremely variable. More importantly, they can vary within a very short time. Information obtained only one hour ago may not be valid or may become unavailable. Obtaining the real-time information is extremely important to create a flexible production processes. Therefore, textile manufacturing industries should be more flexible to meet customers' variable requests. Today's production systems used in the textile and clothing industries are not sufficiently flexible. One of the most important reasons of this is to the use of traditional production methods in the textile manufacturing processes. These methods are extremely static and they do not show dynamic characteristics. The assembly line technique of mass production is still used in many textile and clothing industries. They are designed to produce standard products and cannot produce personalized and customized products. Finally, they cannot respond adequately to customer requirements.

In the near future, textile industry and value chain have to review their production systems in the light of approaches relating to smart factories, advanced production technologies and industry 4.0. Their production systems should be reconfigured according to the new paradigms of the fourth industrial revolution. Primarily, new textile production systems should be more flexible and variations related to material flows should be developed depending on the variety of products.

Advanced technology used in smart factories can lead to more flexible production processes and material flow systems. New production technologies can provide real-time information relating to variable customer requests. Different solutions can automatically be determined according to different customer requirements in textile industries. On the other hand, solutions created by the system may be independent from each other.

Intelligent production systems can lead to the creation of optimal material flow systems. In addition to that, self-configuration of the production process is possible under variable conditions. In this way, functions of machines will become more complex in the near future. In the same way, production methods and material flows will be more complicated. Therefore, it will become almost impossible to carry out effective and efficient production and logistics 
activities without advanced production technologies. Since self-optimization of the material flow systems provided by advanced digital technologies can automatically be obtained, the resource use may be reduced. In this way, industries can create efficient manufacturing processes and can execute these operations effectively. Consequently, competitive advantages can be obtained depending on intelligent production systems in the textile industry. Machines can communicate with each other and devices and this will lead to autonomic textile process chains.

Interaction among machines will be the main element of the production and logistics operations in the near future. On the other hand, communication between human and machines will be more developed. The use of smart devices will result in variations in manufacturing processes. Smart devices can be used to obtain real-time information relating to customer requirements. Also, customers can directly be participants of value chain processes. Programming the manufacturing operations will become possible with the real-time information provided by customers' smart devices in the near future.

\section{CONCLUSIONS}

While the world continues to change, today's winds of change are much more powerful and lead to change almost in all aspects of our lives. Impacts of the fourth industrial revolution has recently begun to be felt. These impacts are particularly strong in the manufacturing industries. Impacts of the fourth industrial revolution has recently begun to be felt. According to many manufacturing industrialists, they will be even more powerful in the near future than today. Consequently, many large-scale companies will lose their competitiveness if they remain indifferent to these developments.

Textile and clothing industries should be aware of the new paradigms on the brink of the fourth industrial revolution. In the coming years, becoming a smart factory will be one way to meet customer requirements as a result of the extremely variable market conditions. In this way, textile industry can solve its structural problems arising from intensive labour use, energy costs, and market uncertainties. At the same time, they can increase the efficiency and the productivity in the production processes, and logistics operations can be carried out at high levels of performance.

\section{REFERENCES}

[1] J. Lee, Smart Factory Systems, Springer-Verlag Berlin Heidelberg, pp. 230-235, 2015

[2] K. Moser, "Mass customization strategies: Development of a competence-based framework for identifying different mass customization strategies," Lulu Enterprises, p. 129, 2007.
[3] S. Wang, J. Wan, D. Li, and C. Zhang, "Implementing smart factory of industries 4.0: An outlook," International Journal of Distributed Sensor Networks, pp. 1-10, 2016.

[4] D. Zuehlke, "Smart Factory - towards a factory-of-things," Annual Reviews in Control, vol. 34, pp. 129-138, 2010.

[5] F. Shrouf; J. Ordieres, G. Miragliotta, "Smart factories in Industry 4.0: A review of the concept and of energy management approached in production based on the Internet of Things paradigm," in Proc. 2014 IEEE International Conference on Industrial Engineering and Engineering Management, 2014, p. 697-701.

[6] I. Stojmenovic and F. Zhang, "Inaugural issue of "cyber-physical systems," Cyber-Physical Systems, vol. 1, pp. 1-4, 2015.

[7] N. Jazdi, "Cyber physical systems in the context of industry 4.0, automation, quality and testing, robotics," in Proc. 2014 IEEE International Conference, 2014, pp. 1-4.

[8] E. Lee. (May 2008). Cyber physical systems: Design challenges. University of California, Berkeley Technical Report No. UCB/EECS-2008-8. [Online]. Available: http://www.eecs.berkeley.edu/Pubs/TechRpts/2008/EECS-2008-8.ht $\mathrm{ml}$

[9] V. Paelke, "Augmented reality in the smart factory: Supporting workers in an industry 4.0. Environment," in Proc. 2014 IEEE Emerging Technology and Factory Automation (ETFA), Barcelona, pp. 1-4, 16-19 Sept.2014.

[10] B. Hameed, J. Minguez, M. Wömer, P. Hollstein, S. Zor, S. Silcher, F. Dürr, and K. Rothermel, "The smart real-time factory as a product service system, functional thinking for value creation," in Proc. the $3 r d$ CIRP International Conference on Industrial Product Service Systems, 2011, pp. 326-331.

[11] M. Rüßmann, M. Lorenz, P. Gerbert, M. Waldner, J. Justus, P. Engel, and M. Harnisch. (April 2015). Industry 4.0: Future of the Productivity. Boston Consulting Group's BCG Perspectives. pp. 21. [Online]. Available:

http://www.bcg.com.cn/export/sites/default/en/files/publications/repo rts_pdf/BCG_Industry_40_Future_of_Productivity_April_2015_ENG .pdf

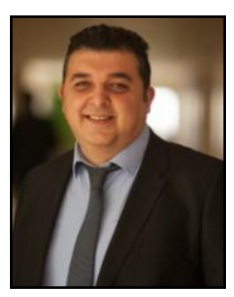

Ömer F. Görçün was born in Istanbul in 1976. He received his Ph.D. in Institution Marine Science and Administration from Istanbul University. Görçün's research focus on the technology in logistics and manufacturing processes. His studies are interested not only in logistics, supply chain management and manufacturing processes but also transportation and warehouse management. Actually, he focuses on technologic improvements in IT and its using opportunities in these processes.

Görçün is Deputy Dean of Applied Science Faculty and member of International Trade and Logistics Department at the Kadir Has University. He tried to form a logistics department and logistics labs that are used for technologic investigation and researches.

Görçün's studies were published as scientific books as forth Industrial Revolution: Industry 4.0, supply chain management, warehouse and Inventory management, Information and Communication System in Logistic, Transportation Management. In addition to that, he gave successful examples of scientific studies as paper relating to these topics. He has numerous scientific studies which related to logistics, supply chain management, technologic improvements in manufacturing and logistics processes and using the technologic instruments in supply chains. 